\title{
O Programa Nacional da Educação na Reforma Agrária - PRONERA em "desmonte": 20 anos de lutas e conquistas ameaçados pelo elitismo fundiário no cenário de 2016 a 2020
}

\author{
Guilherme Martins Teixeira Borges ${ }^{1}$, Maria Esperança Fernandes Carneiro ${ }^{2}$ \\ ${ }^{1}$ Centro Universitário de Goiás - UNIGOIÁS. Faculdade de Direito e Pró-reitoria de Ensino a Distância. Avenida João Candido \\ de Oliveira, 115, Cidade Jardim. Goiânia - GO. Brasil. ${ }^{2}$ Pontifícia Universidade Católica de Goiás - PUC/GO. \\ Autor para correspondência/Author for correspondence: g.martins.borges@hotmail.com
}

\begin{abstract}
RESUMO. O presente trabalho tem como objetivo analisar a correlação histórica entre as políticas públicas fundiárias e as educacionais e como essas inter-relações influenciaram os movimentos sociais do campo a lutar por seus direitos sociais, em especial pelo direito à educação, por meio da criação do Programa Nacional da Educação na Reforma Agrária - PRONERA. Assim, este estudo parte da análise histórica para a crítica atual frente aos inúmeros instrumentos utilizados pelas diretrizes governamentais do país, do ano de 2016 até 2020, como formas de deslegitimar o direito à educação no campo para os trabalhadores rurais e desestruturar o PRONERA, de uma vez por todas. Para compreender esta problemática, foram eleitas como categorias de pesquisa: o Capitalismo, a exploração, a propriedade privada, a reforma agrária, o trabalho e a educação. Quanto ao processo metodológico, foram contempladas as categorias teóricas de análise científica contempladas pelo referencial materialista-histórico dialético, dada a configuração social e política do objeto de estudo. Em relação às metodologias de pesquisa o trabalho está construído via levantamento de pesquisa teórica bibliográfica e documental. Para esse percurso de pesquisa, foram empregados como marcos teóricos estruturantes autores como Roseli Salete Caldart (2012), Isabel Brasil Pereira (2002), Paulo Alentejano (2002), Gaudêncio Frigotto (2002), dentre outros. Ao final, a pesquisa possibilitou destacar como os ataques aos direitos sociais, em especial dos trabalhadores rurais, tem sido uma das pautas escancaradas das elites brasileiras e que, aliadas ao projeto neoliberal extremista, tem tanto no PRONERA, mas também em considerável parte das políticas fundiárias de pauta social, uma ameaça aos interesses econômicos das elites do país.
\end{abstract}

Palavras-chaves Pronera, Educação do Campo, Capitalismo Agrário, Políticas Públicas.

\begin{tabular}{|l|l|l|l|l|l|l|} 
RBEC & Tocantinópolis/Brasil & v. 5 & e10501 & $10.20873 /$ uft.rbec.e10501 & 2020 & ISSN: 2525-4863 \\
\hline
\end{tabular}




\title{
The National Program of Education in Agrarian Reform - PRONERA in "dismantling": 20 years of struggles and conquests threatened by the elitism fundiário no cenario from 2016 to 2020
}

\begin{abstract}
The present work aims to analyze the historical correlation between public land and educational policies and how these interrelationships influenced social movements in the countryside to fight for their social rights, especially for the right to education, through creation of the National Program for Education in Agrarian Reform - PRONERA. Thus, this study starts from the historical analysis for the current criticism in view of the numerous instruments used by the country's governmental guidelines, from the year 2016 to 2020, as ways to delegitimize the right to education in the field for rural workers and to disrupt PRONERA, once for all. To understand this problem, they were chosen as research categories: Capitalism, exploitation, private property, land reform, work and education. As for the methodological process, the theoretical categories of scientific analysis contemplated by the dialectical materialisthistorical framework were used, given the social and political configuration of the object of study. Regarding the research methodologies used, the work is constructed via a survey of bibliographical and documentary theoretical research. For this research path, authors like Roseli Salete Caldart (2012), Isabel Brasil Pereira (2002), Paulo Alentejano (2002), Gaudêncio Frigotto (2002), among others, were used as structuring theoretical frameworks. In the end, the research made it possible to highlight how the attacks on social rights, especially of rural workers, have been one of the wide-open agendas of Brazilian elites, which, together with the extremist neoliberal project, have so much in PRONERA, but also in a considerable part of policies of social issues, a threat to the economic interests of the country's elites.
\end{abstract}

Keywords: Pronera, Rural Education, Agrarian Capitalism, Public Policies. 


\section{El Programa Nacional de Educación en Reforma Agraria - PRONERA en "desmantelamiento": 20 años de luchas y conquistas amenazadas por el elitismo basado en la tierra en el escenario de 2016 a 2020}

RESUMEN. El presente trabajo tiene como objetivo analizar la correlación histórica entre la tierra pública y las políticas educativas y cómo estas interrelaciones influyeron en los movimientos sociales del campo para luchar por sus derechos sociales, especialmente por el derecho a la educación, a través de la creación del Programa Nacional de Educación en Reforma Agraria - PRONERA. Así, este estudio parte del análisis histórico de la crítica actual ante los numerosos instrumentos utilizados por los lineamientos gubernamentales del país, desde el año 2016 al 2020, como vías para deslegitimar el derecho a la educación en el campo de los trabajadores rurales y para trastocar PRONERA. De una vez por todas. Para entender este problema, se eligieron como categorías de investigación: capitalismo, explotación, propiedad privada, reforma agraria, trabajo y educación. En cuanto al proceso metodológico, se utilizaron las categorías teóricas de análisis científico contempladas por el marco histórico-materialista dialéctico, dada la configuración social y política del objeto de estudio. En cuanto a las metodologías de investigación empleadas, el trabajo se construye a través de un relevamiento de la investigación teórica bibliográfica y documental. Para este camino de investigación, autores como Roseli Salete Caldart (2012), Isabel Brasil Pereira (2002), Paulo Alentejano (2002), Gaudêncio Frigotto (2002), entre otros, fueron utilizados como marcos teóricos estructurantes. Al final, la investigación permitió resaltar cómo los ataques a los derechos sociales, especialmente de los trabajadores rurales, han sido una de las agendas abiertas de las élites brasileñas y que, junto con el proyecto neoliberal extremista, tienen tanto en PRONERA, pero también en una parte considerable de las políticas de los problemas sociales, una amenaza para los intereses económicos de las élites del país.

Palabras clave: Pronera, Educación Rural, Capitalismo Agrario, Políticas Públicas. 


\section{Introdução}

O presente artigo analisa o processo de desestruturação das políticas públicas educacionais voltadas ao campo, sobretudo a partir do ano de 2016, no Governo de Michel Temer, com a escancarada política econômica ultraliberal estabelecida no país.

Dentre essas medidas desestruturantes, um dos pontos de maior preocupação, no referido governo, se deu com o "desmonte" do Programa Nacional da Educação na Reforma Agrária PRONERA, que representa um dos mais importantes instrumentos de promoção da Educação do Campo no Brasil.

A relevância dessa compreensão se torna bastante atual, sobretudo diante do contexto social e político no qual o Brasil se encontra desde 2016 (Governos dos Presidentes Michel Temer e Jair Bolsonaro). Educação não é mais prioridade nas ações no Ministério da Educação, o campo, o espaço rural, a terra, o meio ambiente equilibrado e todos que deles, sustentavelmente vivem, não têm mais proteção contra os comandos das recentes políticas de governos.

De fato, manter o trabalhador rural distante dos meios de produção e do acesso à educação é uma estratégia de massificação de mão de obra, porém, as razões de tratar os direitos à Reforma
Agrária e à Educação como ameaças estão ligados à própria manutenção da superestrutura do capital.

O modelo político-econômico comandado pelas elites brasileiras mantém um rígido, para não dizer violento, controle sobre a democratização do acesso aos bens rurais no país. Isso porque, os direitos de Reforma Agrária, caso efetivamente implementados, representariam uma ruptura com o ciclo exploratório do capital, que desde os modelos escravocratas de exploração tornam, ora a terra escrava, ora o trabalhador ou mesmo os dois em seus cativeiros político-econômicos.

Para compreender essas questões, foi utilizado como aporte teórico metodológico o materialismo-histórico dialético, pois, dada a configuração social e política do objeto de estudo, caracterizado pelo movimento das ideias e dos diversos grupos de interesse que compõem o contexto do campo brasileiro e do acesso à educação e seus entrelaços com as políticas públicas educacionais e fundiárias, as categorias teóricas de análise científica contempladas pelo referencial materialista-histórico dialético, foram essenciais para os fins da abordagem desse artigo. Já em relação à metodologia, o trabalho está construído via pesquisa teórica e bibliográfica. 

"desmonte": 20 anos de lutas e conquistas ameaçados pelo elitismo fundiário no cenário de 2016 a $2020 \ldots$

\section{Um esboço histórico do Programa Nacional da Educação na Reforma Agrária - PRONERA}

O Programa Nacional da Educação na Reforma Agrária - PRONERA constitui o principal documento regulamentador da Política Pública para a Educação do Campo. O programa passou a ser uma importante fonte que conecta as políticas de Reforma Agrária e a promoção da educação do campo, nas mais diversas peculiaridades que o ambiente rural necessita.

O PRONERA foi fruto de um processo de lutas e reivindicações dos camponeses, dos movimentos sociais agrários, dos setores públicos e privados que se preocupavam com a delicada situação que afligia a educação nas áreas rurais.

É nesse contexto que a atuação dos movimentos sociais agrários foi importante para a discussão da Educação do Campo:

No âmbito da educação para áreas rurais, o paradigma da Educação do Campo vai ser a base para esses programas e políticas públicas, a partir de então. Nesse momento, inicia-se no interior das práticas educativas dos movimentos sociais um processo de construção de pedagogias próprias dos sujeitos da luta pela terra. Esses sujeitos também passam a construir suas próprias escolas e princípios políticoideológicos que deram forma a um modelo de educação que visa reproduzir as formas camponesas no campo, valorizando seus próprios sujeitos (Oliveira, 2017, pp. 18-19).

Tais discussões foram fortalecidas com a promulgação da Lei de Diretrizes e Bases da Educação Nacional (LDB), em 20 de dezembro de 1996, que passou a prever em seu artigo 28 a possibilidade de currículo e metodologias apropriadas ao meio rural e imprimiu maior compreensão das especificidades e singularidades na organização escolar em relação ao calendário escolar dessas localidades.

Outro fator importante, embora não seja o único movimento social voltado às pautas fundiárias, foi a participação do Movimento dos Trabalhadores Rurais Sem-Terra (MST) neste processo, o que possibilitou articular e dar maior visibilidade ao I Encontro Nacional de Educadores da Reforma Agrária (ENERA), no ano de 1997, que também teve a participação do Grupo de Trabalho de Apoio à Reforma Agrária da Universidade de Brasília (GT-RA/UnB), do Fundo das Nações Unidas para a Infância (UNICEF), do Fundo das Nações Unidas para a Ciência e Cultura (UNESCO) e da Conferência Nacional dos Bispos do Brasil (Borges \& Carneiro, 2016).

Estas articulações passaram a ser chamadas de Movimento pela Luta de uma Educação do Campo que deu origem a outras iniciativas, uma delas, oriunda dos 
trabalhos do I ENERA, criou um grupo eleito para coordenar a produção do processo de construção de um projeto educacional das instituições de ensino superior nos assentamentos, responsável pela elaboração de um documento (textobase do PRONERA), apresentado no III Fórum do Conselho de Reitores das Universidades Brasileiras, ocorrido nos dias 6 e 7 de novembro de 1997.

Em 16 de abril de 1998, por meio da Portaria n. ${ }^{\circ}$ 10/98, o extinto Ministério Extraordinário de Política Fundiária, à época chefiado pelo ministro Raul Jungmann, criou o Programa Nacional de Educação na Reforma Agrária (PRONERA), bem como a sua primeira versão do Manual de Operações.

Assim, o PRONERA se formaliza como um programa de governo resultante dos progressos pelos quais a discussão e a luta, que envolvem a Reforma Agrária, empreenderam no país na década de noventa, juntamente com uma atuação mais incisiva do Movimento dos Trabalhadores Sem-Terra, um processo em que, além da discussão fundiária, também passava a debater outros direitos inerentes a luta pela terra, como por exemplo, o direito à educação:

O programa [PRONERA] criado por portaria do então Ministério Extraordinário da Política Fundiária (MEPF), num contexto de ascensão da luta pela Reforma Agrária que aliava as condições de forte organização e mobilização dos Sem Terra por todo o território nacional à sensibilidade da sociedade brasileira em torno da causa, mobilizada após os massacres de Corumbiara, em Rondônia, em 1995, e de Eldorado dos Carajás, no Pará, em 1996. Os movimentos sociais do campo souberam bem aproveitar este ambiente favorável à Reforma Agrária para trazer a público outras pautas normalmente esquecidas ou desconhecidas pelas autoridades, entre elas a situação da Educação no Campo, notadamente a falta de escolas, e a falta de educadores para as poucas que existiam, o que impunha uma condição de acesso apenas aos anos escolares iniciais, reproduzindo, nos assentamentos, a mesma lógica de negação histórica do direito, aos camponeses, de acesso aos níveis mais elevados de escolaridade (Caldart, Pereira, Alentejano \& Frigotto, 2012, p. 632).

Essa proximidade entre o PRONERA, enquanto política pública, e a atuação dos movimentos sociais do campo foi e ainda é, um dos principais fatores que permitiu ao programa produzir bons resultados, "pois foi uma luta que veio desde baixo" (Oliveira, 2017, p. 22) e conseguiu se projetar como uma política pública fundiária e educacional a ser promovida em todo país, respeitando as particularidades da identidade do povo camponês e de sua luta pela terra.

Por outro lado, ao se tornar um forte instrumento de luta em favor dos trabalhadores do campo, sobretudo para os assentados e beneficiários da Reforma 
Agrária, o PRONERA tem representado uma ameaça às elites agrárias do país.

Logo, com base nas considerações apontadas, há algo que se pode inferir: o PRONERA se insere no processo de lutas de classes dos trabalhadores do campo face às elites e ao agronegócio.

Nos primeiros anos do programa, a maior preocupação se deu em razão dos altos índices de analfabetismos dos moradores do campo, em especial aqueles que viviam em assentamentos para fins de Reforma Agrária. Havia, portanto, uma patente necessidade de se efetivar processos de escolarização da população rural brasileira, o que se deu por meio da Educação de Jovens e Adultos. Em 13 anos o programa realizou 167 cursos para nível fundamental em todos os Estados e no Distrito Federal, proporcionando uma maior disseminação e visibilidade do PRONERA pelo país (Instituto de Pesquisa Econômica Aplicada, 2015, p. 26).

Na década de 2000 novas demandas por parte dos movimentos sociais exigiram do PRONERA outras abordagens educacionais voltadas para a promoção do ensino médio e do ensino superior:

Em razão destes resultados, o Pronera, que até então executava majoritariamente projetos de alfabetização e escolarização em séries iniciais, passou a incentivar projetos de ensino fundamental completo e nível médio. Com o desenvolvimento destes projetos, a consequente conclusão deste nível de ensino e a necessidade de formação de professores para as escolas conquistadas para os PAs, os próprios movimentos sociais passaram a demandar projetos de cursos superiores, inicialmente restritos à área de Pedagogia e licenciaturas, posteriormente ampliados para outras áreas, como as de Ciências Agrárias. (Caldart et al., 2012, p. 632).

Assim, todos os movimentos mencionados foram de suma importância para potencializar o PRONERA como marco regulatório das políticas públicas de Educação do Campo, tanto que em 2010, por meio do Decreto n. ${ }^{\circ} 7.352 / 10$ é definitivamente incorporado como uma política pública de Estado e não somente de Governo.

Além disso, a sua execução passou a ficar a cargo do Instituto Nacional de Colonização e Reforma Agrária - INCRA. A incorporação do PRONERA à gestão do INCRA foi relevante para uma melhor estruturação do programa junto ao contexto dos assentamentos rurais e dos movimentos sociais do campo, uma vez que a atuação do INCRA é realizada direta e indiretamente junto dessas comunidades agrárias.

Em seus vinte anos de história, o PRONERA/INCRA, desde a sua criação em 1998, manteve-se muito proativo na promoção de políticas públicas educacionais para o campo: 
Firmou convênios com universidades públicas e qualificou quase $200 \mathrm{mil}$ brasileiros do campo. Os dados apontam para mais de 165 mil brasileiros atendidos pela Educação de Jovens e Adultos - EJA que puderam ser alfabetizados, concluir o Ensino Fundamental e Médio. Para além disso, o PRONERA formou mais de 5 mil graduados e 3 mil pósgraduados. Adicionalmente, mais de 20 mil brasileiros do campo tiveram acesso a cursos de extensão. (Pinheiro, 2020, p. 3).

Em termos legais, o PRONERA é regulamentado por 19 (dezenove) disposições normativas em seu Decreto regulador, que tratam de assuntos que vão desde a organização do programa aos cuidados com seus aspectos técnicos como, por exemplo, os relativos à gestão orçamentária, bem como com os princípios norteadores da Educação do Campo. Outro documento importante é o Manual de Operações do PRONERA, aprovado em sua atual edição pela Portaria/INCRA/P/N. - 19, de 15 de janeiro de 2016, cujo conteúdo aprofunda as logísticas de cooperações e parcerias do programa com as entidades de ensino.

Segundo o Manual, o objetivo do PRONERA é fortalecer a educação nas áreas de Reforma Agrária estimulando, propondo, criando, desenvolvendo e coordenando projetos educacionais, utilizando metodologias voltadas para a especificidade do campo, tendo em vista contribuir para a promoção da inclusão social com desenvolvimento sustentável nos Projetos de Assentamento da Reforma Agrária.

Já nos termos do Decreto n. $^{\circ}$ 7.352/10, o PRONERA tem três objetivos centrais bem definidos, quais sejam: a) oferecer educação formal aos jovens e adultos beneficiários do Plano Nacional de Reforma Agrária - PNRA, em todos os níveis de ensino; b) melhorar as condições do acesso à educação do público do PNRA; e, c) proporcionar melhorias no desenvolvimento dos assentamentos rurais por meio da qualificação do público do PNRA e dos profissionais que desenvolvem atividades educacionais e técnicas nos assentamentos.

Em relação aos princípios elencados no programa vamos fazer uma longa citação, ainda que, possa ser cansativa, dada as especificidades do público beneficiário em questão, podemos agrupálos em duas categorias. Um primeiro grupo que trata dos princípios políticopedagógico do PRONERA, e um segundo que versa diretamente sobre os princípios orientadores da proposta de Educação do Campo.

São seis os princípios básicos de natureza político-pedagógica do programa:

a) Democratização do acesso à educação: a cidadania dos jovens e adultos que vivem nas áreas de 
reforma agrária será assegurada, também, por meio da oferta de uma educação pública, democrática e de qualidade, sem discriminação e cuja responsabilidade central seja dos entes federados e suas instituições responsáveis e parceiras nesse processo.

b) Inclusão: a indicação das demandas educativas, a forma de participação e gestão, os fundamentos teóricos metodológicos dos projetos devem ampliar as condições do acesso à educação como um direito social fundamental na construção da cidadania dos jovens e adultos que vivem nas áreas de reforma agrária.

c) Participação: a indicação das demandas educacionais é feita pelas comunidades das áreas de reforma agrária e suas organizações, que em conjunto com os demais parceiros decidirão sobre a elaboração, execução e acompanhamento dos projetos.

d) Interação: as ações desenvolvidas por meio de parcerias entre órgãos governamentais, instituições de ensino públicas e privadas sem fins lucrativos, comunidades assentadas nas áreas de reforma agrária e as suas organizações, no intuito de estabelecer uma interação permanente entre esses sujeitos sociais pela via da educação continuada e da profissionalização no campo.

e) Multiplicação: A educação do público beneficiário do PRONERA visa a ampliação do número de trabalhadores rurais alfabetizados $\mathrm{e}$ formados em diferentes níveis de ensino, bem como, garantir educadores, profissionais, técnicos, agentes mobilizadores e articuladores de políticas públicas para as áreas de reforma agrária.

f) Participação social: o PRONERA se desenvolve por meio de uma gestão participativa, cujas responsabilidades são assumidas por todos os envolvidos na construção, acompanhamento e avaliação dos projetos pedagógicos. A parceria é condição essencial para a realização das ações do PRONERA. Os principais parceiros são os movimentos sociais e sindicais do campo, as instituições de ensino públicas e privadas sem fins lucrativos e os governos municipais e estaduais. (INCRA - Manual de Operações do Programa Nacional de Educação na Reforma Agrária, 2016, pp. 14-15).

A par desta análise, podemos aferir que o PRONERA tem três dimensões de constituição: jurídica, pedagógica e de política pública. A dimensão jurídica do programa é dada pelo próprio decreto que o regulamenta ao cuidar de aspectos eminentemente vinculados ao direito, tais como a fixação de competências legislativas e administrativas aos entes federados (artigos $3^{\circ}, 4^{\circ}, 7^{\circ}, 9^{\circ}$ dentre outros). A segunda dimensão, de natureza pedagógica, é expressa pela série de disposições do programa que trazem as premissas do que é a Educação do Campo para o PRONERA, tanto que no artigo $2 .^{\circ}$ do decreto regulamentador são elencados os diversos princípios da educação do campo. E, por fim, a dimensão de política pública, que talvez seja a natureza mais aproximada das finalidades do PRONERA, na medida em que se torna um projeto voltado a consecução de políticas públicas do campo e da educação, simultaneamente. 

"desmonte": 20 anos de lutas e conquistas ameaçados pelo elitismo fundiário no cenário de 2016 a $2020 \ldots$

Ademais, inegável também é o papel dessa dimensão em constituir o PRONERA com vistas a promover um conjunto de ações afirmativas para as comunidades campesinas, aos beneficiários e assentados da reforma agrária, bem como aos agricultores familiares.

Considerando, ainda, a dimensão de política pública do PRONERA, podemos afirmar que, de forma inovadora, o programa também expressa seu importante papel como instrumento de promoção das ações afirmativas que são medidas que visam, a médio e longo prazo, tentar amenizar as consequências negativas de um processo histórico de exclusão social dos habitantes do campo que lhes dificultou o acesso aos direitos fundamentais de um ser humano, a exemplo do próprio direito à educação.

Assim, as ações afirmativas constituem medidas de compensação pela falha no cumprimento do mandamento da Constituição Federal brasileira, que em seu artigo $5^{\circ}$, caput, garante, dentro outros direitos fundamentais, a igualdade formal e material.

Em uma leitura estritamente jurídica o direito à igualdade se desenvolve numa perspectiva formal e substancial. Tais acepções expressam a ideia de que, embora todos os seres humanos sejam iguais entre si, historicamente, diversos grupos sociais foram excluídos do acesso a direitos e, por essa razão, é preciso tratar de forma igual os iguais e de maneira desigual os desiguais. A isto damos o nome de "fator discriminação" (Mello, 2003).

Portanto, tendo em vista a realidade social de nosso país, as ações afirmativas são fatores de discriminação positivos na medida em que buscam por meio de instrumentos de compensação, amenizar as enormes disparidades sociais em razão de fatores econômicos, etnia, sexo dentre outros.

No campo da educação superior as ações afirmativas ganharam destaque com a promulgação, no ano 2000 , da Lei n. ${ }^{\circ}$ 3.524 do Estado do Rio Janeiro que de forma inovadora destinou $50 \%$ (cinquenta por cento) das vagas das Universidades fluminenses a estudantes que tivessem cursado integralmente o ensino médio nas redes públicas estaduais ou municipais. No ano seguinte foi publicada a Lei $n .^{\circ}$ 3.708/2001, também do Estado do Rio de Janeiro, que passou a reservar $40 \%$ (quarenta por cento) das vagas dos vestibulares da Universidade Estadual do Rio de Janeiro - UERJ e da Universidade Estadual do Norte Fluminense - UENF para negros e pardos.

Após essas iniciativas diversas Universidades brasileiras seguiram os mesmos passos, tais como a Universidade 

"desmonte": 20 anos de lutas e conquistas ameaçados pelo elitismo fundiário no cenário de 2016 a $2020 \ldots$

de Brasília - UNB e a Universidade do Estado da Bahia - UNEB e, no ano de 2002, o Governo Federal promulgou a Lei n. ${ }^{\circ} 10.550$, por intermédio da qual se criou o "Programa Diversidade na Universidade".

Este contexto trouxe um verdadeiro chacoalhar sobre os modelos tradicionais nos quais se desenvolvia o ensino superior no país. Isso porque $\mathrm{o}$ acesso às Universidades brasileiras sempre fora um privilégio das classes mais abastadas e um "não-direito" do trabalhador, do negro, do pobre. Não é por menos que tais políticas de cotas foram levadas ao questionamento no Supremo Tribunal Federal - STF, por meio da Arguição de Descumprimento de Preceito Fundamental n. ${ }^{\circ}$ 186-02/DF proposta, em 20 de julho de 2009, pelo partido político Democratas (DEM). Nesta ação de constitucionalidade o referido partido político insurgiu contra os atos administrativos da Universidade de Brasília - UNB em relação à sua política de ações afirmativas e à criação das cotas raciais.

Vejamos alguns trechos da ADPF n. - 186-02/DF e as alegações do DEM contrárias às ações afirmativas:

Alega-se ofensa aos artigos $1^{\circ}$, caput e inciso III; $3^{\circ}$, inciso IV; $4^{\circ}$, inciso VIII; $5^{\circ}$, incisos I, II, XXXIII, XLII, LIV; 37, caput; 205; 207, caput; e 208, inciso V, da Constituição de 1988.
A peça inicial defende, em síntese, que “... na presente hipótese, sucessivos atos estatais oriundos da Universidade de Brasília atingiram preceitos fundamentais diversos, na medida em que estipularam a criação da reserva de vagas de $20 \%$ para negros no acesso às vagas universais e instituíram verdadeiro 'Tribunal Racial', composto por pessoas nãoidentificadas e por meio do qual os direitos dos indivíduos ficariam, sorrateiramente, à mercê da discricionariedade dos componentes...”.

Alega que o sistema de cotas da UnB pode agravar $\mathrm{o}$ preconceito racial, uma vez que institui a consciência estatal da raça, promove ofensa arbitrária ao princípio da igualdade, gera discriminação reversa em relação aos brancos pobres, além de favorecer a classe média negra (Supremo Tribunal Federal. Arguição de Descumprimento de Preceito Fundamental n. 186-02/DF, 2002).

Todavia, neste caso específico, o direito à Educação saiu vitorioso, tendo o Supremo Tribunal Federal reconhecido a legitimidade das ações afirmativas realizadas pela UNB. Tal decisão gerou efeitos em todo o país:

Ementa: Arguição de Descumprimento de Preceito Fundamental. Atos que instituíram sistema de reserva de vagas com base em critério étnico-racial (cotas) no processo de seleção para ingresso em instituição pública de ensino superior. Alegada ofensa aos arts. $1^{\circ}$, caput, iii, $3^{\circ}$, iv, $4^{\circ}$, viii, $5^{\circ}$, i, ii xxxiii, xli, liv, 37, caput, 205, 206, caput, i, 207, caput, e 208, v, todos da Constituição Federal. Ação julgada improcedente. I - Não contraria - ao contrário, prestigia - o princípio da igualdade material, previsto no caput do art. $5^{\circ}$ da Carta 
da República, a possibilidade de o Estado lançar mão seja de políticas de cunho universalista, que abrangem um número indeterminado de indivíduos, mediante ações de natureza estrutural, seja de ações afirmativas, que atingem grupos sociais determinados, de maneira pontual, atribuindo a estes certas vantagens, por um tempo limitado, de modo a permitir-lhes a superação de desigualdades decorrentes de situações históricas particulares. II O modelo constitucional brasileiro incorporou diversos mecanismos institucionais para corrigir as distorções resultantes de uma aplicação puramente formal do princípio da igualdade. III - Esta Corte, em diversos precedentes, assentou a constitucionalidade das políticas de ação afirmativa. IV Medidas que buscam reverter, no âmbito universitário, o quadro histórico de desigualdade que caracteriza as relações etnicorraciais e sociais em nosso País, não podem ser examinadas apenas sob a ótica de sua compatibilidade com determinados preceitos constitucionais, isoladamente considerados, ou a partir da eventual vantagem de certos critérios sobre outros, devendo, ao revés, ser analisadas à luz do arcabouço princípio lógico sobre o qual se assenta o próprio Estado brasileiro... (Brasil, Supremo Tribunal Federal. Arguição de Descumprimento de Preceito Fundamental n. ${ }^{\circ}$ 18602/DF, 2002).

Como esperado, esse resultado não agradou às elites brasileiras, pelo contrário, representou praticamente um objetivo de sua parte manejar atos contra as ações afirmativas.

Infelizmente, o que resultou em quase 20 anos de evolução e garantia de direitos sociais fundamentais no campo da
Educação parece hoje estar ameaçado no Estado que deu origem aos programas de ações afirmativas em nosso país. O atual Deputado Estadual Rodrigo Amorim (PSL), do Rio de Janeiro, que também é advogado, propôs em maio de 2019 o Projeto de Lei n. ${ }^{\circ}$ 470/2019, que tem por finalidade única extinguir as ações afirmativas para pessoas negras nas Universidades estaduais cariocas.

Assim justifica o deputado as razões do seu projeto:

Cotas raciais sempre dividem negativamente as sociedades onde são implantadas, gerando o ódio racial e o ressentimento das pessoas que não entraram na Universidade, apesar de terem obtido nota maior ou igual à obtida pelos cotistas nas provas de vestibular.

As cotas definidas pela cor da pele do indivíduo corrompem as Universidades onde são aplicadas, aniquilando o valor do mérito acadêmico e criando pressões sem fim para discriminar as pessoas por sua 'raça' em todos os níveis de ensino, do fundamental à universidade.

Cada vez mais são noticiados casos de candidatos que fraudam as auto declarações raciais no intuito de fazerem jus a uma vaga que na verdade não fazem. Tal critério jamais poderia ser utilizado para defender direitos, já que não é possível atestar a real necessidade de um candidato apenas pela cor da sua pele.

O referido sistema representa uma afronta à meritocracia já que todos são iguais perante a lei e, permitir um sistema de cotas que utiliza como critério a cor da pele causa uma distorção nos direitos universais, pois considera que a cor da pele define a 
incapacidade do indivíduo de buscar por seus próprios méritos o objetivo que deseja alcançar.

$\mathrm{O}$ presente projeto visa extinguir a possibilidade da divisão social instituída através do sistema de cota racial que buscou garantir um suposto direito de ingresso nas universidades públicas do estado definido apenas pela cor da pele do indivíduo, e manter somente o direito à cota para aqueles estudantes que necessitam de fato do referido sistema, por conta de fatores que de fato os prejudica e não apenas pela cor da pele. (Assembleia Legislativa do Estado do Rio de Janeiro Projeto de Lei n. $\left.{ }^{\circ} 470,2019\right)$.

As motivações do deputado, em que pese seu elevado grau de absurdos na construção das ideias e análises apontadas, causa-nos ainda maior perplexidade porque representa uma parcela considerável do pensamento da população brasileira, afinal tal candidato foi o mais votado nas eleições de 2018.

Ao final de sua justificativa, de que é preciso "manter somente o direito à cota para aqueles estudantes que necessitam de fato do referido sistema, por conta de fatores que de fato os prejudica e não apenas pela cor da pele", o desvelar dos interesses que ele representa são escancarados em sua proposta legislativa, pois segundo o projeto: "Fica extinto o sistema de cotas para ingresso nas universidades estaduais no âmbito do Estado do Rio de Janeiro, adotado com a finalidade de assegurar seleção e classificação final nos exames vestibulares aos estudantes carentes, exceto:" filhos de policiais civis e militares, bombeiros militares, inspetores de segurança e administração penitenciária, mortos ou incapacitados em razão de suas atribuições (PL n. ${ }^{\circ}$ 470/2019).

Ora, por qual subjugação histórica, social e política passaram os militares de nosso país para justificar sua inclusão em programas de ação afirmativa? Não existe. Porém, ciclicamente, a estrutura do capital por meio da classe dominante sempre tentará alijar as duras conquistas das minorias brasileiras no campo da Educação. Por fim, realizadas essas considerações gerais sobre as ações afirmativas, como podemos compreender o PRONERA inserido em tal categoria?

Em que pese a relevante conquista do "Programa Diversidade na Universidade", mais uma vez os trabalhadores do campo, em sua maioria, também ficaram às margens desses benefícios, pois ainda prepondera uma visão urbanocêntrica que direciona as políticas públicas educacionais no Brasil e, no caso das ações afirmativas, a situação não foi diferente: o trabalhador do campo não foi contemplado.

Entretanto, se por um lado as ações afirmativas mais recorrentes buscavam enfrentar o processo histórico de exclusão 
dos negros e pobres de centros urbanos, tivemos, por outro lado, o Programa Nacional da Educação da Reforma Agrária surgindo como um forte instrumento de "fator discriminação" positivo em prol dos trabalhadores rurais.

\section{O PRONERA como "ameaça" e as ações governamentais atuais para seu desmonte}

As ações de desmonte do Programa Nacional de Educação na Reforma Agrária ganharam mais força a partir do ano de 2016, com o golpe parlamentar, militar, jurídico e midiático, que contou, também, com interesses internacionais adjacentes que impuseram o ultra neoliberalismo, sobretudo com a emenda constitucional $n .^{\circ}$ 95/2016, também conhecida como a "PEC da Morte", quando ainda tramitava na Câmara dos Deputados e no Senado. Essa emenda impôs políticas de congelamento orçamentário durante o governo do expresidente Michel Temer (2016 a 2019).

Por consequência, tais medidas impactaram drasticamente nas políticas sociais, em especial aquelas voltadas à educação, a saúde, a segurança, a previdência social, a assistência, fragilizando ainda mais a rede de proteção social do país.

A perspectiva político-econômica ultra neoliberal do Governo Temer teve por programa a agressiva privatização dos bens públicos, preservação do rendimento dos rentistas e banqueiros, destruição da legislação trabalhista, cortes de recursos sociais da saúde, cultura e educação, concentração da renda e marginalização social.

Tal perspectiva ultra neoliberal cortou os recursos do PRONERA, conforme constou das diretrizes para a elaboração e execução da Lei Orçamentária de 2019, que chegavam a aproximadamente R $\$ 30$ milhões em 2016, pela metade em 2017 e, no ano de 2018, foram previstas verbas de apenas cerca $R \$$ 7 milhões para o exercício do programa em 2019 (Brasil, Câmara dos Deputados, 2019).

O governo atual, do Presidente Jair Bolsonaro (2019 a 2020), deu continuidade às políticas ultra neoliberalistas do governo Temer, mas também ao neoconservadorismo, tendo por intuito, como aponta Santos (2020, p. 22), “... calar as vozes da classe operária, dos trabalhadores rurais e urbanos, da juventude, das mulheres, dos indígenas, dos sem-terra, dos sem teto, dos negros, e de todos os trabalhadores que sofrem exploração, dominação e opressão".

Podemos constatar como os cortes de recursos para o PRONERA constituem-se em política de alijamento social dos trabalhadores rurais, na medida em que, 
conforme os últimos dados do Anuário Brasileiro da Educação Básica 2019, somente $29,8 \%$ das crianças que residem nas áreas rurais apresentam nível suficiente de alfabetização em leitura, ao passo que as crianças que estudam na zona urbana apresentam suficiência de 47,7\% (Brasil, Anuário Brasileiro da Educação Básica 2019, p. 52), fatos estes que indicam a necessidade de os habitantes da zona rural terem direito a uma atenção especial. Além disso, também no ensino superior essa realidade é constatada:

Segundo o Observatório do PNE (2017), baseado na Pesquisa Nacional por Amostra de Domicílios do IBGE, indica que, em 2019, a taxa líquida de matrícula na educação superior das populações rurais era de $6,5 \%$, e a taxa líquida do quartil mais rico era de $41,5 \%$ e o do quartil mais pobre da população, de somente $6,9 \%$, e, por fim, a vergonhosa desigualdade que nos indica que a taxa líquida de matrícula na educação superior da população branca era quase o dobro das taxas das populações negras e indígenas. (Brasil, Pesquisa Nacional de amostras por domicílio, 2019).

Ricardo Vélez Rodríguez, primeiro ministro da educação do governo Bolsonaro (jan.2019/abr.2019), em entrevista ao Jornal Valor Econômico afirma que: "a ideia de universidade para todos não existe", e ainda acalora, "as universidades devem ficar reservadas para uma elite intelectual, que não é a mesma elite econômica do país" (Brasil, Valor Econômico, 2019).

A segunda nomeação para ministro da educação no governo do presidente Jair Bolsonaro (2019) foi o economista Abraham Weintraub "de falas e postura polêmica, denunciando rapidamente seu perfil autoritário e antidemocrático, explicitando medidas para uma gestão marcada pelo contingenciamento de gastos na pasta da educação" (Santos, 2020, p. 30). Em sua gestão constatou-se cortes das verbas para a educação, de modo geral, e em especial para as Universidades que promovem as maiores parcerias de projetos vinculados ao PRONERA, portanto, desde o início do mencionado governo já se temia a inviabilização do programa.

O Ministro supracitado comentou, em 30 de abril de 2019, em entrevista ao jornal Estado de São Paulo, a respeito dos primeiros cortes aos recursos das universidades, dentre as quais estavam a UFF, UFBA e UNB, que perderiam $30 \%$ (trinta por cento) de seus orçamentos. No entanto, as justificativas do governo para os cortes, explanadas pelo então Ministro, tiveram um teor extremamente politizado de cunho neoliberal na forma de se pensar a Educação, bem como acerca do que se espera da posição das elites do país frente ao direito de acesso a uma educação emancipadora. 
Vejamos a representatividade desse discurso:

'Universidades que, em vez de procurar melhorar o desempenho acadêmico, estiverem fazendo balbúrdia, terão verbas reduzidas', disse o ministro.

De acordo com Weintraub, universidades têm permitido que aconteçam em suas instalações eventos políticos, manifestações partidárias ou festas inadequadas ao ambiente universitário. 'A universidade deve estar com sobra de dinheiro para fazer bagunça e evento ridículo', disse. Ele deu exemplos do que considera bagunça: "Sem-terra dentro do campus, gente pelada dentro do campus.

Weintraub não detalhou quais manifestações ocorreram nas universidades citadas, mas disse que esse não foi o único ponto observado. Essas instituições também estão apresentando resultados aquém do que deveriam, disse. "A lição de casa precisa estar feita: publicação científica, avaliações em dia, estar bem no ranking." Ele, no entanto, não citou rankings. (Brasil, Estadão, 2019).

A posição do Ministro da Educação Abraham Weintraub, que em sua formação profissional é economista, deixa claro que o fomento ao pensamento crítico dentro das universidades, sobretudo as públicas, será retaliado pelo governo por meio de medidas de cortes em investimentos e uma maior gerência do Estado dentro das universidades e institutos federais.

Nesta visão, portanto, as ações do PRONERA e todos os seus resultados e frutos que persistem até os dias atuais, são consideradas "balbúrdias", como, por exemplo, "Sem-terra dentro do campus". Ora, essa fala do Ministro é praticamente a reprodução do mesmo discurso ideológico da classe dominante de que lugar de trabalhadores do campo não é na escola, ao menos não naquelas que preparam os alunos criticamente para entender as mazelas da exploração capitalista.

Em outra oportunidade, também se posicionaram em redes públicas o Presidente Jair Bolsonaro e novamente o Ministro da Educação Abraham Weintraub, as suas preocupações com as escolas de sem-terra:

O presidente Jair Bolsonaro criticou nesta quinta-feira o que chamou de 'forte doutrinação ideológica' de cerca de 200 mil alunos pobres e de áreas rurais que frequentam aproximadamente duas mil escolas, nas palavras de Bolsonaro, 'ditas Sem Terrinha', geridas pelo Movimento dos Trabalhadores Rurais Sem Terra (MST). Postado ao lado de Bolsonaro no momento da fala, o ministro da Educação, Abraham Weintraub, aproveitou para defender o fim do repasse de dinheiro público para escolas do movimento.

- Ali (nas escolas do MST), dia sim, dia não, em vez de o Hino Nacional e o hasteamento da bandeira, se canta a Internacional Socialista ou o hino do MST. E há uma forte doutrinação ideológica nessa garotada. No meu entender, não tem que ter política em sala de aula. Nem de esquerda nem de direita. Ou, se tiver, que tenha os dois lados - disse o presidente, para quem a 'garotada' deve sair da escola sabendo interpretar textos, a fórmula da água ou uma regra de três simples. 
- (Nossa intenção é) que tenhamos no futuro, na ponta da linha, bons profissionais e não bons militantes. $\mathrm{O}$ que, no meu entender, não é bom para o Brasil - complementou.

Já o ministro da Educação, depois de destacar que $30 \%$ das crianças brasileiras não estão na pré-escola e deveriam ter preparo para não chegarem defasadas e em desvantagem na primeira série do ensino fundamental, disse que o objetivo é deslocar alunos das escolas do MST 'para dentro da República', através de assistência, de creches, pré-escola. Para o ministro, as escolas não podem ser 'uma coisa fora da nação brasileira'.

$\mathrm{Na}$ mesma linha da fala do ministro, Bolsonaro manifestou disposição de colocar o governo para intervir na 'questão ideológica' das escolas do MST.

- Agora, na questão ideológica, eu acho que o Estado poderia interferir. Não podemos deixar que se formem militantes ou brasileiros que não terão qualquer qualificação no futuro, que seriam apenas dependentes do Estado em outras áreas - declarou Bolsonaro, sendo questionado, em seguida, sobre de que forma $o$ governo atuar nesse espaço.

- O que for possível fazer, a gente faz. A gente quer que a escola forme bons profissionais, bons patrões, bons empregados, bons liberais. Isso é coisa para mais de dez anos, mas tem que ter o primeiro passo respondeu. (Brasil, O Globo, 2019).

Além desses dados objetivos, o que nos causa mais espanto são as demais medidas tomadas pelos dirigentes públicos que demonstram um nítido ataque aos movimentos sociais e sindicais de trabalhadores e trabalhadoras do campo, quilombolas, comunidades tradicionais e ao próprio INCRA.
$\mathrm{Na}$ reestruturação política do INCRA, promovida pelo governo, nomeou-se o coronel César Augusto Gerken para a coordenação nacional do PRONERA (Portaria n. ${ }^{\circ} 741$, de 15 de abril de 2019). Conforme os dados informados pelo próprio INCRA, o currículo do novo gestor do programa o apresenta como:

Coronel do Exército, com experiência em gestão nacional e internacional, formado na Academia Militar das Agulhas Negras (AMAN), tem pós-graduação em Administração Pública na Universidade Castelo Branco (UCB) e em Bases Geo-históricas para Formação Estratégica na Escola de Comando e Estado-Maior do Exército (ECEME). É mestre em Ciências Militares, cursado na Escola de Aperfeiçoamento de Oficiais (EsAO), tem curso superior de Defesa na Escola Superior de Guerra (ESG), curso de Política Estratégica e Alta Administração do Exército na ECEME e MBA Executivo em Administração na Fundação Getúlio Vargas (FGV). Participou de duas missões de Paz no Haiti.

Não há, portanto, nenhuma formação profissional do novo coordenador na área da Educação, tampouco vínculo com demandas correlacionadas a questões agrárias e, menos ainda, com movimentos sociais. Nesse mesmo contexto, o atual Governo também extinguiu todos os Conselhos, Comissões e outros mecanismos de participação social, 

"desmonte": 20 anos de lutas e conquistas ameaçados pelo elitismo fundiário no cenário de 2016 a $2020 \ldots$

eliminou também a Comissão Pedagógica Nacional do PRONERA.

Outra discussão merecedora de destaque é a vinculação do PRONERA ao INCRA e, consequentemente, ao atual Ministério da Agricultura. Sob uma visão estritamente objetiva e, até certo ponto, pragmática, a incorporação do PRONERA à gestão do INCRA foi relevante para uma melhor estruturação do programa junto ao contexto dos assentamentos rurais e dos movimentos sociais do campo, vez que a atuação do INCRA é realizada direta e indiretamente junto dessas comunidades agrárias, nos assentamentos e demais programas fundiários. Todavia, em um aprofundamento mais crítico sobre esta questão, deve-se, no mínimo causar estranheza, um programa de política pública educacional como o PRONERA não fazer parte do Ministério da Educação, mas sim de uma autarquia federal vinculada ao Poder Executivo no âmbito da União.

A exemplo disso, programas educacionais que também possuem suas pautas voltadas a educação do campo são gerenciados pelo Ministério da Educação, conforme dados disponibilizados em seu sítio eletrônico oficial, o Governo brasileiro possui as seguintes ações vinculadas à promoção de educação do campo: a) PRONACAMPO; b) PROLIND
- Apoio à Formação Superior e Licenciaturas Interculturais Indígenas; c) PET Conexões de Saberes; e UNIAFRO Ações Afirmativas para a População Negra no Educação Superior (Brasil, Ministério da Educação, 2020).

Embora essa discussão seja bem mais complexa, o que se revela nesse ponto é justamente a constatação de como os projetos de educação no campo no cenário da Reforma Agrária revelam seus espaços de lutas e de contradições. A conquista da educação do campo, portanto, está imbricada nos processos de luta por reforma agrária (Ribeiro, 2011, p. 26).

Essa situação, somada às perspectivas de cortes às ações do PRONERA, ocasionaram a realização de uma Audiência Pública, em 11/07/2019, sobre o programa. Dentre os convidados presentes estavam Deborah Duprat Procuradora Federal dos Direitos do Cidadão (MPF), Edjane Rodrigues Silva Secretária de Políticas Sociais da Contag, representando o Fórum Nacional de Educação do Campo (Fonec), Clarice Aparecida dos Santos - Doutora em Políticas Públicas e Professora do Curso de Licenciatura em Educação do Campo da Universidade de Brasília, Edward Madureira Brasil - Reitor da Universidade Federal de Goiás e Maria de Jesus dos Santos Gomes - Representante do 
Movimento dos Trabalhadores Sem Terra (MST).

Destacamos algumas das falas pontuadas pelos participantes:

A redução do empenho de recursos no âmbito do Pronera observada nos últimos anos foi apontada pela procuradora como fator crítico à manutenção do Programa. Segundo ela, em 2013 o valor representava cerca de R\$ 27 milhões, chegando em 2018 a aproximadamente $\mathrm{R} \$ 5$ milhões. 'O Pronera praticamente não existe'. (Deborah Duprat)

... o Pronera inspirou as bases de implementação de uma política nacional de educação no campo, defendendo a sua manutenção no âmbito do Instituto Nacional de Colonização e Reforma Agrária (Incra). 'O que nós queremos é um campo com gente vivendo com qualidade e dignidade. E quando a gente retira os direitos daqueles que estão no campo nós estamos comprometendo a produção de alimentos saudáveis no nosso país. Nós estamos contribuindo com a saída da nossa juventude do campo'. (Edjane Rodrigues Silva).

'... O Pronera desafiou as instituições de ensino e a ciência a pensar sobre as questões trazidas pelo povo do campo', destacou a professora ao ressaltar que os camponeses passaram a apresentar à academia problemas ligados à produção, à organização social das comunidades rurais e à educação no campo. A redução dos índices de analfabetismo nas áreas rurais, acrescentou, também se deu em função da existência do Programa Nacional de Educação na Reforma Agrária. (Clarice Aparecida dos Santos).

... o Pronera possibilitou a formação de diversos profissionais, como pedagogos, veterinários, agrônomos e advogados. Todos sabemos como foi difícil cada universidade quebrar o elitismo da educação nesse país. (Maria de Jesus dos Santos Gomes). (Procuradoria Federal dos Direitos do Cidadão, 2019).

Em conclusão, notamos que o ataque aos direitos sociais, em especial dos trabalhadores rurais, tem sido uma das pautas escancaradas das elites brasileiras e que, aliadas ao projeto neoliberal extremista, vê no PRONERA uma ameaça. Assim, se realmente este for o fim do programa, não há dúvidas de que ele foi uma política pública fundiária e também educacional efetiva e eficaz que despertou a classe dominante.

\section{Considerações finais}

O golpe final dado pelo atual governo frente às políticas de educação para o campo se concretizou por meio da publicação do Decreto n. ${ }^{\circ} 20.252$ de 20 de fevereiro de 2020, cujo conteúdo versa sobre a reorganização da estrutura do Instituto Nacional de Colonização e Reforma Agrária (INCRA), em uma clara opção pelo enfraquecimento de programas importantes para o desenvolvimento dos Movimentos Sem-Terra e Quilombolas.

$\mathrm{Na}$ reestruturação, o governo extinguiu a Coordenação-Geral de Educação do Campo e Cidadania do âmbito do Instituto Nacional de Colonização e Reforma Agrária (Incra), o 

"desmonte": 20 anos de lutas e conquistas ameaçados pelo elitismo fundiário no cenário de 2016 a $2020 \ldots$

que inviabiliza a continuidade das ações do PRONERA no país. Além disso, toda a política de educação do campo migra sua competência do INCRA, cuja autonomia era essencial para as atividades promovidas no contexto do PRONERA e se estabelece no Ministério da Agricultura, Pecuária e Abastecimento, cujo perfil atual é notadamente voltado ao agronegócio, ou seja, nenhum órgão governamental ficou responsável pela execução do PRONERA.

As manifestações, sejam as dos jornais ou dos dirigentes do Estado brasileiro, demonstram que a luta de classes sempre existiu na história agrária brasileira e, necessariamente, também se reflete na história da educação. A formação das contradições se constrói, de um lado, entre os instrumentos de dominação das elites, suas ascensões aos cargos de direção do Estado e sua agressividade ideológica e, do outro lado, pela atuação de movimentos sociais e pelo fortalecimento de uma educação crítica e emancipadora.

Com isso, é notório que o PRONERA faz parte desse processo de luta de classes que envolve, principalmente, campo e educação e, além disto, sintetizou, até o momento, uma importante conquista dos movimentos sociais agrários frente ao capital e à classe dominante.
Terra e Educação sempre foram grandezas que, na luta de classes da sociedade brasileira, estiveram sob o domínio de uma minoria: dos latifundiários e de sua elite intelectual. E isto, por sua vez, implica dizer que a manutenção do acesso à educação fora da vivência dos trabalhadores da terra é o modo mais seguro de formar e manipular uma massa de mão de obra do campo aos interesses do capital agrário (Borges, 2019, p. 17).

$\mathrm{O}$ direito de acesso aos mais altos e diferentes níveis de Educação é velado pelas elites brasileiras como um privilégio e, por essa razão, não deve ser democraticamente estendido a todos. Manter o trabalhador na ignorância sobre a realidade exploratória em que ele se insere é uma necessidade do sistema capitalista e, por isso, Educação não é para todos, é para poucos.

\section{Referências}

Brasil, Rio de Janeiro - ALERJ. (2019). Projeto de Lei n. 470, de 2019 da Assembleia Legislativa do Estado do Rio de Janeiro. PL 470/19. Dispõe sobre a extinção do sistema de cotas para ingresso nas universidades estaduais no âmbito do Estado do Rio de Janeiro e dá outras providências.

Brasil. (2019). Anuário Brasileiro da Educação Básica. São Paulo: Moderna. Todos pela Educação. 

"desmonte": 20 anos de lutas e conquistas ameaçados pelo elitismo fundiário no cenário de 2016 a $2020 \ldots$

Brasil, Câmara dos Deputados. (2019). Projeto de Lei $n^{\circ}$ 2/2018-CN (MSG $n^{\circ}$ 187/2018-Origem), cria a proposta da Lei de Diretrizes Orçamentárias - LDO 2019 Proposta do Poder Executivo, Brasília-DF.

Brasil, Estadão. (2019). Reportagem "MEC cortará verba de universidade por balbúrdia e já enquadra UNB, UFF e UFBA". Recuperado de https://educacao.estadao.com.br/noticias/ge ral,mec-cortara-verba-de-universidade-porbalburdia-e-ja-mira-unb-uff-eufba,70002809579

Brasil, INCRA - Instituto de Colonização e Reforma Agrária. (2016). Programa Nacional de Educação na Reforma Agrária: Manual de Operações, aprovado pela Portaria/INCRA/P/No 19 , Brasília-DF, de 15 de janeiro de 2016

Brasil, Lei n. 9.394, de 20 de dezembro de 1996. (1996). Estabelece as Diretrizes e Bases da Educação Nacional. Diário Oficial da União, v. 134, n. 248, 1996.

Brasil, Ministério da Educação (2020). Programas e ações da Secretaria de Educação Continuada, Alfabetização, Diversidade e Inclusão (SECADI). Recuperado de http://portal.mec.gov.br/secretaria-deeducacao-continuada-alfabetizacaodiversidade-e-inclusao/programas-e-acoes

Brasil, O Globo. (2019). Reportagem "Bolsonaro critica e ministro fala em tirar dinheiro público de escolas do MST". Recuperado de https://oglobo.globo.com/sociedade/bolson aro-critica-ministro-fala-em-tirar-dinheiropublico-de-escolas-do-mst-23622417.

Brasil, Pesquisa Nacional por Amostra de Domicílios - PNAD. (2019). Instituto Brasileiro de Geografia e Estatística IBGE.
Brasil, Supremo Tribunal Federal. (2002). Arguição de Descumprimento de Preceito Fundamental n. 186-02/DF. Recuperado de http://www.stf.jus.br/arquivo/cms/noticiaN oticiaStfArquivo/anexo/ADPF186.pdf.

Brasil, Valor Econômico. (2019). Reportagem "Ideia de universidade para todos não existe, diz ministro da Educação". Recuperado de https://valor.globo.com/brasil/noticia/2019/ 01/28/ideia-de-universidade-para-todosnao-existe-diz-ministro-da-educacao.ghtml

Borges, G. M. T., \& Carneiro, M. E. F. (2016). Leituras dos 18 anos do Programa Nacional da Educação na Reforma Agrária (PRONERA): uma abordagem a partir do Estado de Goiás. Anais do IV Congresso Nacional da Educação (CONEDU).

Borges, G. M. T. (2019). Educação, campo e contradições: a turma Evandro Lins e silva (UFG/2012) (Tese de Doutorado). Pontifícia Universidade Católica de Goiás, Goiânia.

Caldart, R. S, Pereira, I. B, Alentejano, P., \& Frigotto, G. (2012). Dicionário da Educação do Campo. Rio de Janeiro, São Paulo: Escola Politécnica de saúde Joaquim Venâncio, Expressão popular.

Mello, C. A. B. (2003). O Conteúdo Jurídico do Princípio da Igualdade. $11^{\mathrm{a}}$ tiragem. São Paulo: Malheiros.

Oliveira, M. E. B. (2017). Educação do campo, políticas públicas e movimentos sociais: o papel do Pronera na construção de autonomias relativas. In Foschiera, A. A. (Org.). Educação do campo e o campo de atuação da Escola Família Agrícola de Porto Nacional-TO: Pronera, Agroecologia e Camponeses (pp. 22). Palmas: Nagô Editora. 
Borges, G. M. T., \& Carneiro, M. E. F. (2020). O Programa Nacional da Educação na Reforma Agrária - PRONERA em "desmonte": 20 anos de lutas e conquistas ameaçados pelo elitismo fundiário no cenário de 2016 a $2020 \ldots$

Pinheiro, P. H. (2020). Bolsonaro desmonta INCRA e priva brasileiros do campo da cidadania plena. Recuperado de https://jornalggn.com.br/artigos/bolsonarodesmonta-incra-e-priva-brasileiros-docampo-da-cidadania-plena-por-paulohenrique-pinheiro/

Ribeiro, M. (2011). Educação do Campo e Escola Ativa: contradições na política educacional no Brasil. Educação em Revista, 12(2), 23-40. https://doi.org/10.36311/22365192.2011.v12n2.2485

Santos, L. R. (2020). Políticas públicas: o desmantelamento das políticas do ensino superior no Brasil (Monografia Digital). Pontifícia Universidade Católica de Goiás, Goiânia.

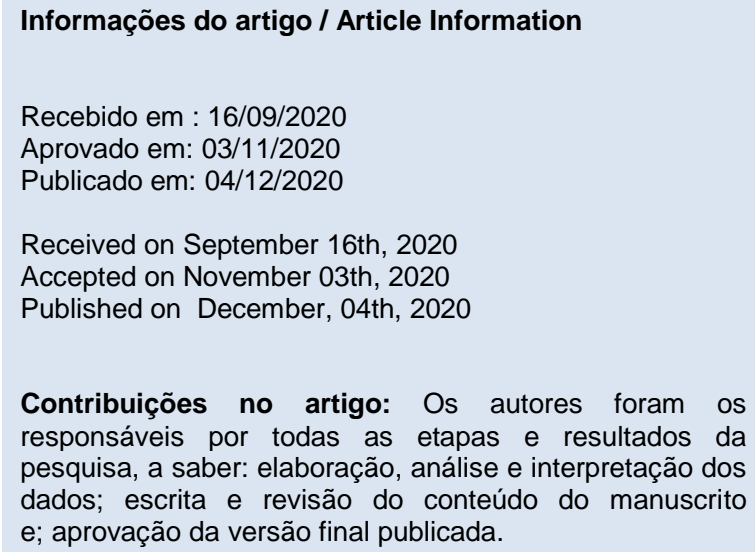

Author Contributions: The author were responsible for the designing, delineating, analyzing and interpreting the data, production of the manuscript, critical revision of the content and approval of the final version published.

Conflitos de interesse: Os autores declararam não haver nenhum conflito de interesse referente a este artigo.

Conflict of Interest: None reported.

\section{Orcid}

Guilherme Martins Teixeira Borges

iD http://orcid.org/0000-0002-9667-8101

Maria Esperança Fernandes Carneiro

iD

http://orcid.org/0000-0002-7272-6666

\section{Como citar este artigo / How to cite this article}

APA

Borges, G. M. T., \& Carneiro, M. E. F. (2020). O Programa Nacional da Educação na Reforma Agrária - PRONERA em "desmonte": 20 anos de lutas e conquistas ameaçados pelo elitismo fundiário no cenário de 2016 a 2020. Rev. Bras. Educ. Camp., 5, e10501. http://dx.doi.org/10.20873/uft.rbec.e10501

\section{ABNT}

BORGES, G. M. T.; CARNEIRO, M. E. F. O Programa Nacional da Educação na Reforma Agrária - PRONERA em "desmonte": 20 anos de lutas e conquistas ameaçados pelo elitismo fundiário no cenário de 2016 a 2020. Rev. Bras. Educ. Camp., Tocantinópolis, v. 5, e10501, 2020. http://dx.doi.org/10.20873/uft.rbec.e10501 